\title{
Evaluation of Distribution of Succinic Acid between Binary Phase System with Biodiesel $+N, N$-Dioctyloctan-1-amine
}

\author{
Sunder Lal Pal ${ }^{1},{ }^{1}$ Shourabh Singh Raghuwanshi, ${ }^{1}$ Kanti Kumar Athankar ${ }^{(D,},{ }^{2,3}$ \\ and Ashwani Kumar Rathore ${ }^{1}$ \\ ${ }^{1}$ Department of Chemical Engineering, Maulana Azad National Institute of Technology, Bhopal 462003, MP, India \\ ${ }^{2}$ Department of Chemical and Biochemical Engineering, Faculty of Chemical and Food Technology, \\ Slovak University of Technology, Bratislava 812 37, Radlinskeho 9, Slovakia \\ ${ }^{3}$ Department of Chemical Engineering, IPS Academy Institute of Engineering \& Science, Indore 452012, MP, India
}

Correspondence should be addressed to Sunder Lal Pal; sunderlalin@gmail.com and Kanti Kumar Athankar; kanti.kumar@ rediffmail.com

Received 29 November 2018; Revised 24 April 2019; Accepted 29 May 2019; Published 18 June 2019

Academic Editor: Maurizio Volpe

Copyright (C) 2019 Sunder Lal Pal et al. This is an open access article distributed under the Creative Commons Attribution License, which permits unrestricted use, distribution, and reproduction in any medium, provided the original work is properly cited.

\begin{abstract}
The present study is aimed at using one of the most promising methods called reactive extraction to extract succinic acid from aqueous solution by using $\mathrm{N}, \mathrm{N}$-dioctyloctan-1-amine in biodiesel as diluent made from sunflower oil, rice bran oil, sesame oil, and karanji oil. The results of extraction studies with the diluents (physical) showed their inability to recover any acid by themselves. In reactive extraction, the organic phase extracting power solely depends on tri- $n$-octylamine. The ranges of the distribution coefficient are found as 7.62-18.12 for sunflower oil biodiesel, 8.33-17.45 for rice bran oil biodiesel, 7.0-17.67 for sesame oil biodiesel, and 9.85-21.36 for karanji oil biodiesel. The ranges of the loading ratio are 0.1-3.0 for sunflower oil biodiesel, $0.1-2.9$ for rice bran oil biodiesel, 0.2-2.9 for sesame oil biodiesel, and 0.1-2.9 for karanji oil biodiesel. The karanji and sunflower oil showed higher values of distribution coefficient $\left(K_{\mathrm{D}}\right)$ over rice bran oil and sesame oil which might be due to presence of both C20 and special fatty acids. The results show that biogenous diluents along with $N, N$-dioctyloctan-1-amine as extractant form a nontoxic and viable option for the extraction of succinic acid in the binary phase system.
\end{abstract}

\section{Introduction}

These days, microorganisms are drawing considerable attention for the production of organic acids like succinic acid not only from the point of view of sustainability but also from the fact that production of these acids can become commercially competitive with production methods using petroleum feedstock. At present, the productivity is low due to product inhibition in the fermentation broth. The costly and complicated separation process is the severe hindrance in the commercialisation of succinic acid production from cheap biomass. There is a need to maintain optimum concentration in the final product to avoid product inhibition by in situ extraction to commercialise the production of succinic acid. Several types of separation approaches such as adsorption, distillation, crystallisation, and membrane processes have been investigated, modelled, and described [1]. In situ extraction of these acids by reactive extraction seems to be a viable option as it can remove the problem of product inhibition. However, the extractants used are toxic to microorganisms, so it is essential to dilute them in the nontoxic diluent for in situ recovery of acids [2]. Presently, succinic acid is produced by using butane via maleic anhydride route in industries. Succinic acid can also be produced from abundant biomass fermentation to produce biodegradable plastics and coatings [3]. It is used as a chemical intermediate, in medicine, in the manufacture of lacquers, and to make perfume esters. It is also used in edible substances as a sequestrant, buffer, and a neutralising agent [4]. The solubility of succinic acid is low in organic solvents, so its extraction needs amines or organophosphorus compounds as an extractant for higher extraction efficiencies $[5,6]$. The removal of succinic acid using a hydrophobic organic phase consisting of tertiary amines dissolved in organic solvents has been 
under investigation by several researchers [7-13]. Recently, the extraction of carboxylic acids with ionic liquids and pressurized carbon dioxide is also gaining considerable importance due to nontoxicity and ease of operation [14-25].

Reactive extraction can be made industrially viable with traditional extractants such as amines and phosphorous compounds only when they are blended with cheap and nontoxic vegetable oils. Many researchers have recently explored this new possibility [26-35]. Recently, biodiesel as extracting solvents was successfully employed to remove aromatic compounds from wastewater and as biodiesels of vegetable oils have very high flash points so acids can be separated with distillation [36]. The present work examined the uptake capacity of biodiesel along with $N, N$ dioctyloctan-1-amine as an extractant for the distribution of succinic acid between binary phase systems.

\section{Materials and Experimental Method}

2.1. Chemicals. Succinic acid and N,N-dioctyloctan-1-amine also known as the tri- $n$-octylamine (TOA) were obtained from Sisco Research Laboratories Pvt. Ltd., Mumbai. These chemicals were used without further purification. The biodiesels of sunflower oil, rice bran oil, sesame oil, and karanji oil were purchased from the local vendor of Bhopal, and their properties are shown in Table 1. Phenolphthalein solution was used as an indicator, and $0.1 \mathrm{~N}$ oxalic acid solution was used for standardization of $\mathrm{NaOH}$ every time. $\mathrm{NaOH}$ was used to determine the aqueous phase acid concentration after phase separation.

2.2. Experimental Setup Used and Procedure. A stock solution of $1 \mathrm{~mol} / \mathrm{L}$ succinic acid in deionised water was prepared by dissolving $118.09 \mathrm{~g}$ of succinic acid (diprotic acid) in a standard measuring flask and its concentration was calculated by titration with $0.1 \mathrm{~N} \mathrm{NaOH}$ solution (although the succinic can be treated as primary standard). The concentration of succinic acid in batch and in anaerobic fermentation was close to $55 \mathrm{~g} / \mathrm{L}[1,7,8]$, so $1 \mathrm{M}$ solution was used as stock solution and desired dilute concentrations were prepared by diluting the stock solution with deionised water. The concentration of $N, N$-dioctyloctan-1-amine in the diluent biodiesel was varied from 10 to $30 \%$ by volume. An equal volume of the aqueous and organic phase, i.e., $10 \mathrm{~mL}$, was taken in a $100 \mathrm{~mL}$ conical flask and shaken in an orbital incubator (Metrex Scientific Instruments Pvt. Ltd., Delhi) at $298 \pm 1 \mathrm{~K}$ for 12 hours to attain equilibrium. After achieving equilibrium, both phases were separated by centrifuging the mixed phase at 6000 RPM for 10 minutes in a centrifuge (REMI R-24, Mumbai). Samples of the aqueous phase were analysed for succinic acid by titration against standardized $\mathrm{NaOH}$, and the acid concentration in organic phase was determined through mass balance. The reproducibility of the data was also checked and found to be within $\pm 3 \%$.

\section{Theory of Reactive Extraction}

3.1. Extraction Equilibrium. The weak carboxylic acids generally do not dissociate in aqueous solution when the $\mathrm{pH}$ of the aqueous solution is smaller than the $\mathrm{p} K_{\mathrm{a}}$ of the acid [2]. The following equation describes the strong reaction of carboxylic acid with TOA extractant resulting in the formation of acid-amine aggregates:

$$
[\mathrm{HA}]_{\mathrm{aq}}+\mathrm{p}[\mathrm{TOA}]_{\mathrm{org}} \stackrel{K_{\mathrm{E}}}{\longleftrightarrow}\left[(\mathrm{HA}) \cdot(\mathrm{TOA})_{\mathrm{p}}\right]_{\mathrm{org}}
$$

By applying the law of mass action, the extraction equilibrium constant $\left(K_{\mathrm{E}}\right)$ reflects the interaction between the extractant and the extracted species according to the following equation:

$$
K_{\mathrm{E}}=\frac{\left[(\mathrm{HA}) \cdot(\mathrm{TOA})_{\mathrm{p}}\right]_{\mathrm{org}}}{[\mathrm{HA}]_{\mathrm{aq}}[\mathrm{TOA}]_{\mathrm{org}}^{\mathrm{p}}}
$$

where $[\mathrm{HA}]_{\mathrm{aq}}$ and $[\mathrm{HA}]_{\text {org }}$ represent the concentration of succinic acid in the aqueous and organic phase, respectively, $[\mathrm{TOA}]_{\text {org }}$ subjected to tri- $n$-octylamine concentration in an organic phase, and $\left[(\mathrm{HA}) \cdot(\mathrm{TOA})_{\mathrm{p}}\right]_{\mathrm{org}}$ represents the complex between succinic acid and extractants in the organic phase. The equilibrium constant, $K_{\mathrm{E}}$, depends upon properties of acid and the solvation (dissolving capacity) of the diluent used. At $\mathrm{pH}$ below $\mathrm{p} K_{\mathrm{a}}$, an acid mostly exists in undissociated form, so the extraction efficiency $(\% E)$ can be calculated in terms of distribution coefficient $\left(K_{\mathrm{D}}\right)$ as

$$
\% E=\frac{K_{\mathrm{D}} \times 100}{\left(1+K_{\mathrm{D}}\right)} \text {. }
$$

3.2. Loading Ratio. The loading ratio (the extent of loading of the organic phase (extractant + diluent) with carboxylic acid) is given below as

$$
Z=\frac{[\mathrm{HA}]_{\mathrm{org}}}{[\mathrm{TOA}]} .
$$

The nature of complexes formed between extractant and acids can be predicted by values of the loading ratio. The various types of complexes that can be formed between acid and extractant are $1: 1,2: 1$, and $3: 1$ and depend on the values of $Z$. For low values of $Z<0.5$, a complex of $1: 1$ is formed. For higher values of $Z>0.5,1: 2$ and $1: 3$ TOA-acid aggregates are formed.

\section{Results and Discussion}

Studies on the physical extraction of succinic acid showed the inability of biodiesel as the diluent to extract acid from the aqueous phase. Therefore, chemical extraction experiments using TOA (10-30\% by volume) in all the four biodiesel diluents were carried out to establish the effect of extractant on the extraction process. The extraction efficiency $(\% E)$, distribution coefficient $\left(K_{\mathrm{D}}\right)$, and loading ratio $(Z)$ for all four diluents are tabulated in Tables 2-5. Significant improvements in extraction efficiency in all four biodiesel diluents along with tri- $n$-octylamine were found.

4.1. Effect of Succinic Acid Concentration on Distribution Coefficient, $K_{D}$. Tables 2-5 show the estimated values of 
TABLE 1: Properties of biodiesel oils used as diluents.

\begin{tabular}{lcccc}
\hline Properties & Sunflower oil biodiesel & Rice bran oil biodiesel & Sesame oil biodiesel & Karanji oil biodiesel \\
\hline Density $\left(\mathrm{kg} / \mathrm{m}^{3}\right)$ & 887.0 & 885.0 & 885.0 & 883.0 \\
Viscosity at $25^{\circ} \mathrm{C}\left(\mathrm{m}^{2} / \mathrm{s}\right)$ & 7.0 & 8.0 & 8.0 & 8.0 \\
Flash point $(\mathrm{PMCC})\left({ }^{\circ} \mathrm{C}\right)$ & 145 & 130 & 140 & 140 \\
Acid value $(\mathrm{mg} \mathrm{KOH} / \mathrm{g})$ & 0.5 & 0.5 & 0.5 & 0.5 \\
\hline
\end{tabular}

TABLE 2: Extraction equilibrium results for succinic acid and TOA in sunflower oil biodiesel at $298 \mathrm{~K}$.

\begin{tabular}{|c|c|c|c|c|c|c|c|c|}
\hline TOA (vol.\%) & {$[\mathrm{HA}]_{\mathrm{o}}(\mathrm{mol} / \mathrm{L})$} & {$[\mathrm{HA}]_{\mathrm{aq}}(\mathrm{mol} / \mathrm{L})$} & {$[\mathrm{HA}]_{\text {org }}(\mathrm{mol} / \mathrm{L})$} & $K_{\mathrm{D}}$ & $K_{\mathrm{D}, \mathrm{avg}}$ & $E(\%)$ & $E_{\text {avg }}(\%)$ & $Z$ \\
\hline 10 & 0.1 & 0.01 & 0.09 & 7.62 & 12.38 & 79.21 & 89.75 & 0.4 \\
\hline 10 & 0.3 & 0.02 & 0.28 & 11.92 & & 92.30 & & 1.2 \\
\hline 10 & 0.5 & 0.03 & 0.47 & 14.13 & & 93.44 & & 2.0 \\
\hline 10 & 0.7 & 0.04 & 0.66 & 15.86 & & 94.08 & & 3.0 \\
\hline 20 & 0.1 & 0.01 & 0.09 & 8.74 & 13.79 & 89.80 & 92.87 & 0.2 \\
\hline 20 & 0.3 & 0.02 & 0.28 & 13.61 & & 93.17 & & 0.6 \\
\hline 20 & 0.5 & 0.03 & 0.47 & 15.97 & & 94.12 & & 1.0 \\
\hline 20 & 0.7 & 0.04 & 0.66 & 16.82 & & 94.39 & & 1.4 \\
\hline 30 & 0.1 & 0.00 & 0.09 & 11.45 & 15.49 & 91.99 & 93.77 & 0.1 \\
\hline 30 & 0.3 & 0.02 & 0.28 & 15.00 & & 93.75 & & 0.4 \\
\hline 30 & 0.5 & 0.03 & 0.47 & 17.36 & & 94.55 & & 0.7 \\
\hline 30 & 0.7 & 0.04 & 0.66 & 18.12 & & 94.79 & & 0.9 \\
\hline
\end{tabular}

TABLE 3: Extraction equilibrium results for succinic acid and TOA in rice bran oil biodiesel at $298 \mathrm{~K}$.

\begin{tabular}{|c|c|c|c|c|c|c|c|c|}
\hline TOA (vol.\%) & {$[\mathrm{HA}]_{\mathrm{o}}(\mathrm{mol} / \mathrm{L})$} & {$[\mathrm{HA}]_{\mathrm{aq}}(\mathrm{mol} / \mathrm{L})$} & {$[\mathrm{HA}]_{\text {org }}(\mathrm{mol} / \mathrm{L})$} & $K_{\mathrm{D}}$ & $K_{\mathrm{D} \text {,avg }}$ & $E(\%)$ & $E_{\text {avg }}(\%)$ & $Z$ \\
\hline 10 & 0.1 & 0.01 & 0.09 & 8.33 & 12.22 & 89.35 & 92.06 & 0.4 \\
\hline 10 & 0.3 & 0.03 & 0.27 & 10.79 & & 91.53 & & 1.2 \\
\hline 10 & 0.5 & 0.03 & 0.47 & 13.54 & & 93.17 & & 2.0 \\
\hline 10 & 0.7 & 0.04 & 0.66 & 16.23 & & 94.21 & & 2.9 \\
\hline 20 & 0.1 & 0.00 & 0.09 & 9.67 & 13.79 & 90.65 & 92.99 & 0.2 \\
\hline 20 & 0.3 & 0.02 & 0.28 & 13.00 & & 92.89 & & 0.6 \\
\hline 20 & 0.5 & 0.03 & 0.47 & 15.47 & & 93.95 & & 1.0 \\
\hline 20 & 0.7 & 0.03 & 0.66 & 17.02 & & 94.49 & & 1.5 \\
\hline 30 & 0.1 & 0.00 & 0.09 & 12.19 & 15.24 & 92.41 & 93.72 & 0.1 \\
\hline 30 & 0.3 & 0.02 & 0.28 & 14.27 & & 93.45 & & 0.5 \\
\hline 30 & 0.5 & 0.02 & 0.47 & 17.07 & & 94.46 & & 0.7 \\
\hline 30 & 0.7 & 0.03 & 0.66 & 17.45 & & 94.57 & & 0.9 \\
\hline
\end{tabular}

TABle 4: Extraction equilibrium results for succinic acid and TOA in sesame oil biodiesel at $298 \mathrm{~K}$.

\begin{tabular}{|c|c|c|c|c|c|c|c|c|}
\hline TOA (vol.\%) & {$[\mathrm{HA}]_{\mathrm{o}}(\mathrm{mol} / \mathrm{L})$} & {$[\mathrm{HA}]_{\mathrm{aq}}(\mathrm{mol} / \mathrm{L})$} & {$[\mathrm{HA}]_{\text {org }}(\mathrm{mol} / \mathrm{L})$} & $K_{\mathrm{D}}$ & $K_{\text {D,avg }}$ & $E(\%)$ & $E_{\text {avg }}(\%)$ & $Z$ \\
\hline 10 & 0.1 & 0.01 & 0.09 & 7.00 & 11.51 & 87.50 & 91.41 & 0.4 \\
\hline 10 & 0.3 & 0.03 & 0.27 & 10.39 & & 91.22 & & 1.2 \\
\hline 10 & 0.5 & 0.04 & 0.46 & 13.18 & & 92.95 & & 2.0 \\
\hline 10 & 0.7 & 0.04 & 0.66 & 15.50 & & 93.99 & & 2.9 \\
\hline 20 & 0.1 & 0.01 & 0.09 & 8.33 & 13.47 & 89.35 & 92.69 & 0.2 \\
\hline 20 & 0.3 & 0.02 & 0.28 & 13.94 & & 93.30 & & 0.6 \\
\hline 20 & 0.5 & 0.03 & 0.47 & 15.00 & & 93.78 & & 1.0 \\
\hline 20 & 0.7 & 0.04 & 0.66 & 16.62 & & 94.34 & & 1.5 \\
\hline 30 & 0.1 & 0.01 & 0.09 & 10.79 & 15.33 & 91.53 & 93.68 & 0.2 \\
\hline 30 & 0.3 & 0.02 & 0.28 & 15.80 & & 94.08 & & 0.5 \\
\hline 30 & 0.5 & 0.03 & 0.47 & 17.07 & & 94.46 & & 0.7 \\
\hline 30 & 0.7 & 0.04 & 0.66 & 17.67 & & 94.65 & & 0.9 \\
\hline
\end{tabular}

distribution coefficients for the chemical extraction by TOA in four diluents for various acid concentrations 0.1-0.7 (mol/L). It was observed that the value of the distribution coefficient increases with the increase in the initial concentration of succinic acid for all diluents which might be due to the limiting factor of the amount of 
TABLE 5: Extraction equilibrium results for succinic acid and TOA in karanji oil biodiesel at $298 \mathrm{~K}$.

\begin{tabular}{|c|c|c|c|c|c|c|c|c|}
\hline TOA (vol.\%) & {$[\mathrm{HA}]_{\mathrm{o}}(\mathrm{mol} / \mathrm{L})$} & {$[\mathrm{HA}]_{\mathrm{aq}}(\mathrm{mol} / \mathrm{L})$} & {$[\mathrm{HA}]_{\text {org }}(\mathrm{mol} / \mathrm{L})$} & $K_{\mathrm{D}}$ & $K_{\mathrm{D} \text {,avg }}$ & $E(\%)$ & $E_{\text {avg }}(\%)$ & $Z$ \\
\hline 10 & 0.1 & 0.01 & 0.09 & 9.85 & 10.42 & 90.78 & 91.26 & 0.4 \\
\hline 10 & 0.3 & 0.03 & 0.27 & 10.07 & & 91.00 & & 1.2 \\
\hline 10 & 0.5 & 0.04 & 0.46 & 10.53 & & 91.38 & & 2.0 \\
\hline 10 & 0.7 & 0.06 & 0.64 & 11.23 & & 91.90 & & 2.9 \\
\hline 20 & 0.1 & 0.01 & 0.09 & 12.51 & 13.88 & 92.59 & 93.23 & 0.2 \\
\hline 20 & 0.3 & 0.02 & 0.28 & 12.72 & & 92.78 & & 0.6 \\
\hline 20 & 0.5 & 0.03 & 0.47 & 13.44 & & 93.13 & & 1.0 \\
\hline 20 & 0.7 & 0.04 & 0.67 & 16.88 & & 94.45 & & 1.4 \\
\hline 30 & 0.1 & 0.01 & 0.09 & 14.10 & 17.71 & 93.41 & 94.56 & 0.1 \\
\hline 30 & 0.3 & 0.02 & 0.29 & 16.43 & & 94.27 & & 0.4 \\
\hline 30 & 0.5 & 0.01 & 0.48 & 18.96 & & 95.03 & & 0.7 \\
\hline 30 & 0.7 & 0.03 & 0.67 & 21.36 & & 95.54 & & 0.9 \\
\hline
\end{tabular}

succinic acid at a low initial acid concentration in all the four cases.

\subsection{Effect of Tri-n-octylamine Concentration on Distribution} Coefficient, $K_{D}$, and Extraction Efficiency, \%E. The diluents were added to decrease the toxicity of extractant, to improve the physical properties of extractant, and to increase the solvation efficiency of the acid-extractant complex. The value of distribution coefficients depends on the type of diluent and concentration of extractant in the diluent. The effect of TOA on distribution coefficients is shown in Tables 2-5. The ranges of $K_{\mathrm{D} \text {,avg }}$ are 12.38-15.49 for sunflower oil biodiesel, 12.2215.24 for rice bran oil biodiesel, 11.51-15.33 sesame oil biodiesel, and 10.42-17.71 for karanji oil biodiesel. Similarly, average values of extraction efficiency, $E_{\mathrm{avg}}$, of $89.75-93.77 \%$ for sunflower oil biodiesel, $92.06-93.72 \%$ for rice bran oil biodiesel, 91.41-93.68\% for sesame oil biodiesel, and 91.26$94.56 \%$ for karanji oil biodiesel were obtained. It is observed that the distribution coefficient increases with the increase in the TOA concentration from $10 \%$ to $30 \%$ at a fixed concentration of succinic acid. The increase is not significant concerning increase in extractant concentration due to the less solvation of the complex in all the diluents (nonpolar) or may be due to the rapid increase in the viscosity of system as shown in Figures 1-3 due to the addition of more extractant. The literature review of extraction with natural oils reveals that the performance of castor oils is better than that of sunflower oil due to presence of special fatty acids. The presence of higher percentage special fatty acid in karanji oils is responsible for its high extraction efficiency when compared with sunflower oil, rice bran oil, and sesame oil fatty acids [37, 38].

\subsection{Effect of Tri-n-octylamine Concentration on Loading} Ratio, $Z$. Tables 2-5 depict the loading values decrease with increasing TOA concentration for all concentrations of succinic acid in all the four diluents. The loading ratio not only decreases with increasing extractant concentration in all the four diluents but also the values of loading ratio are relatively high, i.e., $Z<0.5$ at low TOA concentration for high initial acid concentration. The formation of higher complexes may be due to a lower concentration of TOA. These results are in agreement with the finding of Marti [34] for formic acid. Also, Marti [34] compared the results

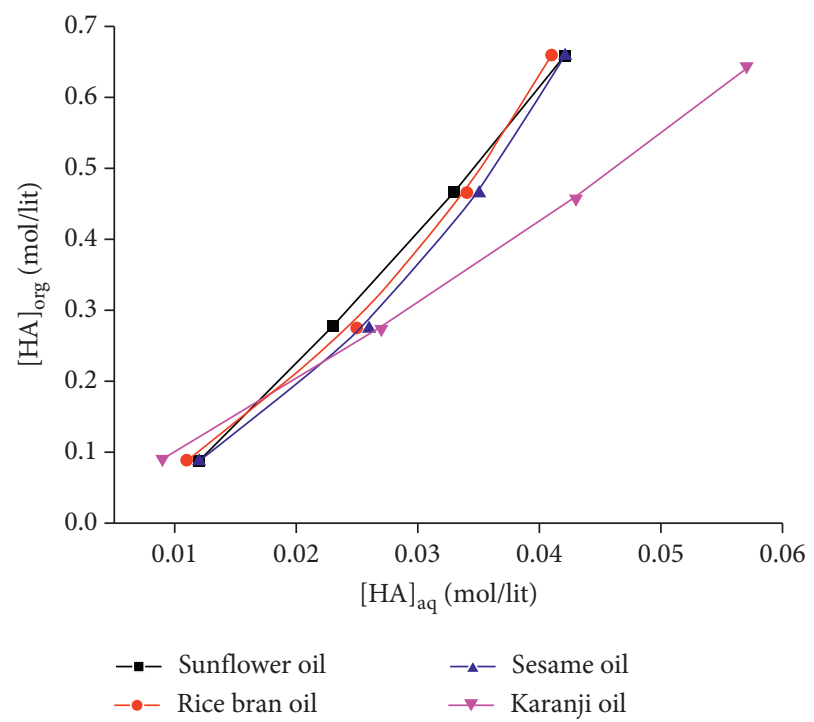

FIgURE 1: Reactive extraction equilibria for succinic acid using $10 \%$ TOA.

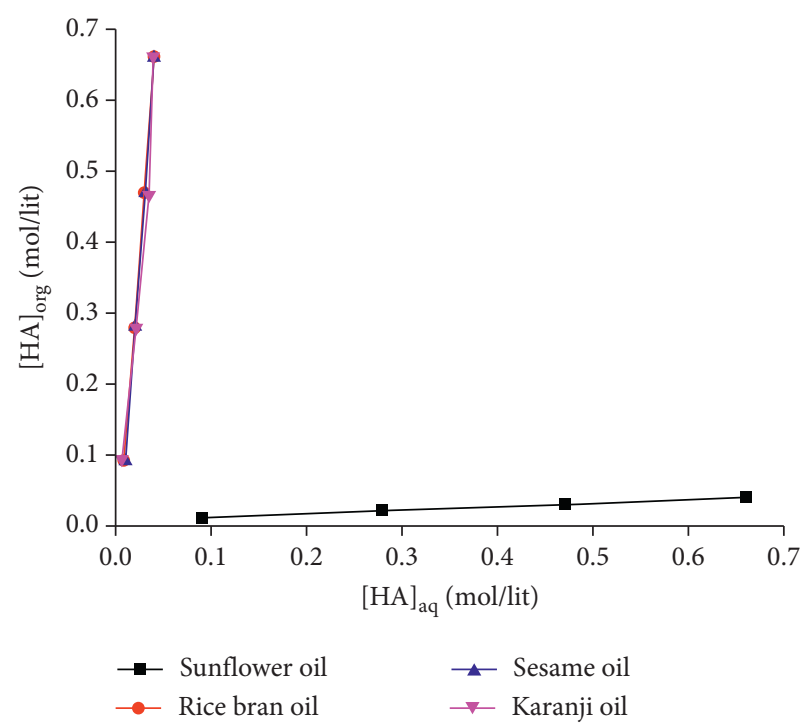

FIgURE 2: Reactive extraction equilibria for succinic acid using $20 \%$ TOA. 


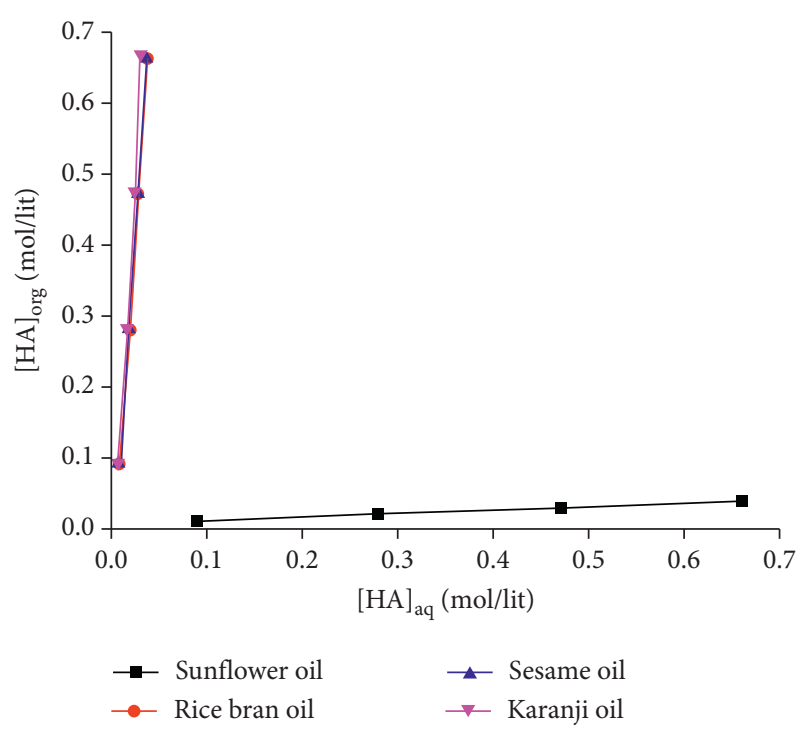

FIgURE 3: Reactive extraction equilibria for succinic acid using $30 \%$ TOA.

of extraction of formic acid using alamine 336 in sunflower oil with alamine octanol system. The values of loading ratio $(Z)$ decrease with the increase in alamine concentration, and at higher initial concentration, often the values of $Z$ are greater than 0.5 , indicating the formation of alamine-acid aggregates [34].

\section{Conclusions}

The extraction of succinic acid using TOA along with biodiesels of sunflower oil, rice bran oil, sesame oil, and karanji oil biodiesel as a diluent was studied. TOA is viscous and toxic too (which is preventing its use for in situ recovery), so it was blended with biodiesel made from sunflower oil, rice bran oil, sesame oil, and karanji oil having low viscosity and toxicity. The distribution coefficient, the degree of extraction, and the loading ratio were determined. The loading ratios were found to be more than $Z>0.5$ in most of the cases $0.1-3.0$ for sunflower oil biodiesel, $0.1-2.9$ for rice bran oil biodiesel, $0.2-2.9$ for sesame oil biodiesel, and 0.1-2.9 for karanji oil biodiesel, respectively. Hence, higher succinic acid-TOA complex formulation was formed in all the diluents. The ranges of $K_{\mathrm{D}}$ are 7.62-18.12, 8.33-17.45, 7.00-17.67, and 9.85-21.36 for sunflower oil biodiesel, rice bran oil biodiesel, sesame oil biodiesel, and karanji oil biodiesel, respectively. The extraction efficiencies are 79.21-94.79\% for sunflower oil biodiesel, $89.35-94.57 \%$ for rice bran oil biodiesel, $87.50-94.65 \%$ for sesame oil biodiesel, and $90.78-95.54 \%$ for karanji oil biodiesel. All the diluents provide a better alternative to oxygen-based petroleum compounds in the extraction of succinic acid, and karanji oil biodiesel serves best among them.

\section{Data Availability}

The experimental data will be shared to verify the results from the corresponding author upon request.

\section{Conflicts of Interest}

The authors declare that they have no conflicts of interest.

\section{References}

[1] T. Kurzrock and D. Weuster-Botz, "Recovery of succinic acid from fermentation broth," Biotechnology Letters, vol. 32, no. 3 , pp. 331-339, 2010.

[2] D. Vandák, J. Zigová, E. Šturdík, and Š. Schlosser, "Evaluation of solvent and $\mathrm{pH}$ for extractive fermentation of butyric acid," Process Biochemistry, vol. 32, no. 3, pp. 245-251, 1997.

[3] I. Bechthold, K. Bretz, S. Kabasci, R. Kopitzky, and A. Springer, "Succinic acid: a new platform chemical for biobased polymers from renewable resources," Chemical Engineering \& Technology, vol. 31, no. 5, pp. 647-654, 2008.

[4] R. K. Saxena, S. Saran, J. Isar, and R. Kaushik, "Production and applications of succinic acid," in Current Developments in Biotechnology and Bioengineering, A. Pandey, S. Negi, and C. R. Soccol, Eds., Elsevier, Amsterdam, Netherlands, pp. 601-630, 2017.

[5] C. J. King, "Separation of processes based on reversible chemical complexation," in Handbook of Separation Process Technology, R. W. Rousseau, Ed., pp. 760-774, Wiley, New York, NY, USA, 1987.

[6] J. G. Zeikus, M. K. Jain, and P. Elankovan, "Biotechnology of succinic acid production and markets for derived industrial products," Applied Microbiology and Biotechnology, vol. 51, no. 5, pp. 545-552, 1999.

[7] Y. K. Hong and W. H. Hong, "Equilibrium studies on reactive extraction of succinic acid from aqueous solutions with tertiary amines," Bioprocess Engineering, vol. 22, no. 6, pp. 477-481, 2000.

[8] Y. K. Hong and W. H. Hong, "Reactive extraction of succinic acid with tripropylamine (TPA) in various diluents," Bioprocess Engineering, vol. 22, no. 4, pp. 0281-0284, 2000.

[9] Y. K. Hong, W. H. Hong, and D. H. Han, "Application of reactive extraction to recovery of carboxylic acids," Biotechnology and Bioprocess Engineering, vol. 6, no. 6, pp. 386-394, 2001.

[10] Y.-S. Jun, E. Z. Lee, Y. S. Huh, Y. K. Hong, W. H. Hong, and S. Y. Lee, "Kinetic study for the extraction of succinic acid with TOA in fermentation broth; effects of $\mathrm{pH}$, salt and contaminated acid," Biochemical Engineering Journal, vol. 36, no. 1, pp. 8-13, 2007.

[11] T. Werpy and G. Petersen, "Top value added chemicals from biomass: volume I-results of screening for potential candidates from sugars and synthesis gas," Report, National Renewable Energy Laboratory, Golden, CO, USA, 2004.

[12] Y. S. Huh, Y.-S. Jun, Y. K. Hong, H. Song, S. Y. Lee, and W. H. Hong, "Effective purification of succinic acid from fermentation broth produced by Mannheimia succiniciproducens," Process Biochemistry, vol. 41, no. 6, pp. 1461-1465, 2006.

[13] Y. S. Aşçı and I. Inci, "Extraction equilibria of succinic acid from aqueous solutions by amberlite LA-2 in various diluents," Journal of Chemical \& Engineering Data, vol. 55, no. 2, pp. 847-851, 2010.

[14] J. Martak and S. Schlosser, "Extraction of lactic acid by phosphonium ionic liquids," Separation and Purification Technology, vol. 57, no. 3, pp. 483-494, 2007.

[15] F. S. Oliveira, J. M. M. Araújo, R. Ferreira, L. P. N. Rebelo, and I. M. Marrucho, "Extraction of L-lactic, L-malic, and succinic 
acids using phosphonium-based ionic liquids," Separation and Purification Technology, vol. 85, pp. 137-146, 2012.

[16] T. Brouwer, M. Blahusiak, K. Babic, and B. Schuur, "Reactive extraction and recovery of levulinic acid, formic acid and furfural from aqueous solutions containing sulphuric acid," Separation and Purification Technology, vol. 185, pp. 186-195, 2017.

[17] A. Krzyżaniak, M. Leeman, F. Vossebeld, T. J. Visser, B. Schuur, and A. B. De Haan, "Novel extractants for the recovery of fermentation derived lactic acid," Separation and Purification Technology, vol. 111, pp. 82-89, 2013.

[18] A. Krzyzaniak, B. Schuur, and A. B. De Haan, "Equilibrium studies on lactic acid extraction with $N, N$-didodecylpyridin-4amine (DDAP) extractant," Chemical Engineering Science, vol. 109, pp. 236-243, 2014.

[19] E. Reyhanitash, T. Brouwer, S. R. A. Kersten, A. G. J. van der Ham, and B. Schuur, "Liquid-liquid extraction-based process concepts for recovery of carboxylic acids from aqueous streams evaluated for dilute streams," Chemical Engineering Research and Design, vol. 137, pp. 510-533, 2018.

[20] E. Reyhanitash, B. Zaalberg, H. M. Ijmker, S. R. A. Kersten, and B. Schuur, " $\mathrm{CO}_{2}$-enhanced extraction of acetic acid from fermented wastewater," Green Chemistry, vol. 17, no. 8, pp. 4393-4400, 2015.

[21] E. Reyhanitash, B. Zaalberg, S. R. A. Kersten, and B. Schuur, "Extraction of volatile fatty acids from fermented wastewater," Separation and Purification Technology, vol. 161, pp. 61-68, 2016.

[22] L. M. J. Sprakel and B. Schuur, "Solvent developments for liquid-liquid extraction of carboxylic acids in perspective," Separation and Purification Technology, vol. 211, pp. 935-957, 2019.

[23] J. Marták and Š. Schlosser, "Liquid-liquid equilibria of butyric acid for solvents containing a phosphonium ionic liquid," Chemical Papers, vol. 62, no. 1, pp. 42-50, 2008.

[24] K. Tonova, I. Svinyarov, and M. G. Bogdanov, "Hydrophobic 3-alkyl-1-methylimidazolium saccharinates as extractants for L-lactic acid recovery," Separation and Purification Technology, vol. 125, pp. 239-246, 2014.

[25] L. M. J. Sprakel and B. Schuur, "Improving understanding of solvent effects on intermolecular interactions in reactive liquid-liquid extraction with isothermal titration calorimetry and molecular modeling," Journal of Industrial and Engineering Chemistry, vol. 72, pp. 364-373, 2019.

[26] T. Harington and M. M. Hossain, "Extraction of lactic acid into sunflower oil and its recovery into an aqueous solution," Desalination, vol. 218, no. 1-3, pp. 287-296, 2008.

[27] H. Uslu, A. Gemici, A. Gök, and Ş. İ. Kurbaşlar, "Reactive extraction of (E)-butenedioic acid (fumaric acid) by nontoxic diluents," Journal of Chemical \& Engineering Data, vol. 59, no. 11, pp. 3767-3772, 2014.

[28] A. Keshav, K. L. Wasewar, and S. Chand, "Extraction of propionic acid using different extractants (tri- $n$-butylphosphate, tri-n-octylamine, and aliquat 336)," Industrial \& Engineering Chemistry Research, vol. 47, no. 16, pp. 6192-6196, 2008.

[29] A. Keshav, K. L. Wasewar, and S. Chand, "Reactive extraction of propionic acid using tri-n-octylamine, tri-n-butyl phosphate and aliquat 336 in sunflower oil as diluent," Journal of Chemical Technology \& Biotechnology, vol. 84, no. 4, pp. 484-489, 2009.

[30] A. Keshav, P. Norge, and K. L. Wasewar, "Reactive extraction of citric acid using tri-n-octylamine in nontoxic natural diluents: part 1-equilibrium studies from aqueous solutions," Applied Biochemistry and Biotechnology, vol. 167, no. 2, pp. 197-213, 2012.

[31] M. D. Waghmare, K. L. Wasewar, S. S. Sonawane, and D. Z. Shende, "Natural nontoxic solvents for recovery of picolinic acid by reactive extraction," Industrial \& Engineering Chemistry Research, vol. 50, no. 23, pp. 13526-13537, 2011.

[32] M. D. Waghmare, K. L. Wasewar, S. S. Sonawane, and D. Z. Shende, "Reactive extraction of picolinic and nicotinic acid by natural non-toxic solvent," Separation and Purification Technology, vol. 120, pp. 296-303, 2013.

[33] K. L. Wasewar, D. Shende, and A. Keshav, "Reactive extraction of itaconic acid using tri-n-butyl phosphate and aliquat 336 in sunflower oil as a non-toxic diluent," Journal of Chemical Technology \& Biotechnology, vol. 86, no. 2, pp. 319-323, 2011.

[34] M. E. Marti, "Recovery of formic acid by reactive extraction using an environmentally-friendly solvent," Selcuk University Journal of Engineering, Science and Technology, vol. 5, no. 1, pp. 26-37, 2017.

[35] A. Kar, A. Bagde, K. K. Athankar, K. L. Wasewar, and D. Z. Shende, "Reactive extraction of acrylic acid with tri-nbutyl phosphate in natural oils," Journal of Chemical Technology \& Biotechnology, vol. 92, no. 11, pp. 2825-2834, 2017.

[36] F. Yu, D. Ji, and J. Ji, "Removal of aromatic compounds from wastewater by biodiesel," in Proceedings of the 2012 International Conference on Computer Distributed Control and Intelligent Environmental Monitoring, pp. 528-531, Hunan, China, March 2012.

[37] Y.-P. Liu, P. Zheng, Z.-H. Sun, Y. Ni, J.-J. Dong, and L.-L. Zhu, "Economical succinic acid production from cane molasses by Actinobacillus succinogenes," Bioresource Technology, vol. 99, no. 6, pp. 1736-1742, 2008.

[38] K. K. Athankar, M. N. Varma, D. Z. Shende, C. K. Yoo, and K. L. Wasewar, "Reactive extraction of phenylacetic acid with tri- $n$-butyl phosphate in benzene, hexanol, and rice bran oil at 298 K," Journal of Chemical \& Engineering Data, vol. 58, no. 11, pp. 3240-3248, 2013. 


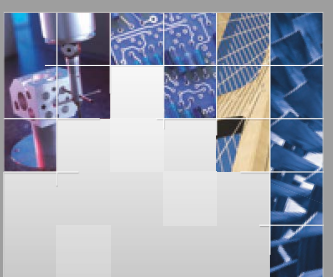

\section{Enfincering}
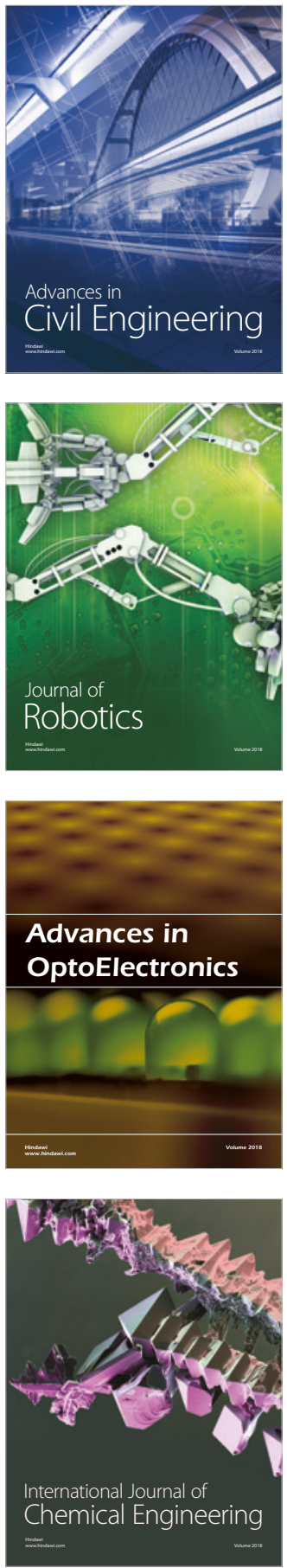

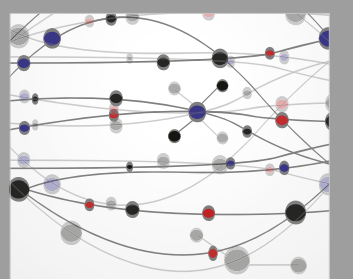

\section{Rotating \\ Machinery}

The Scientific World Journal

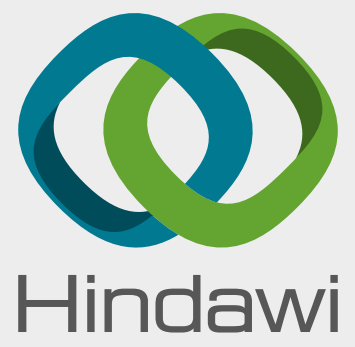

Submit your manuscripts at

www.hindawi.com
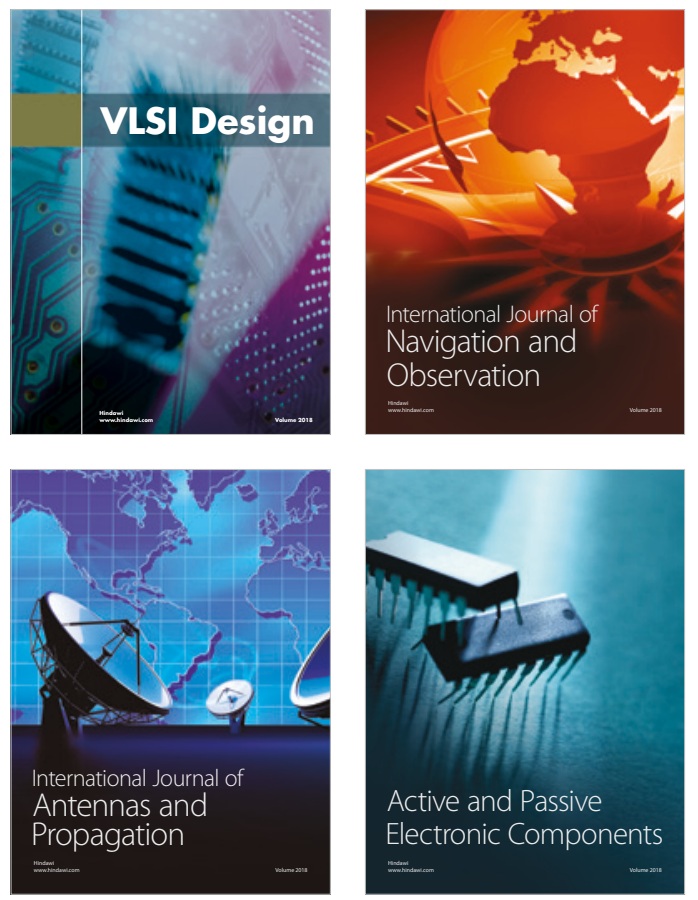
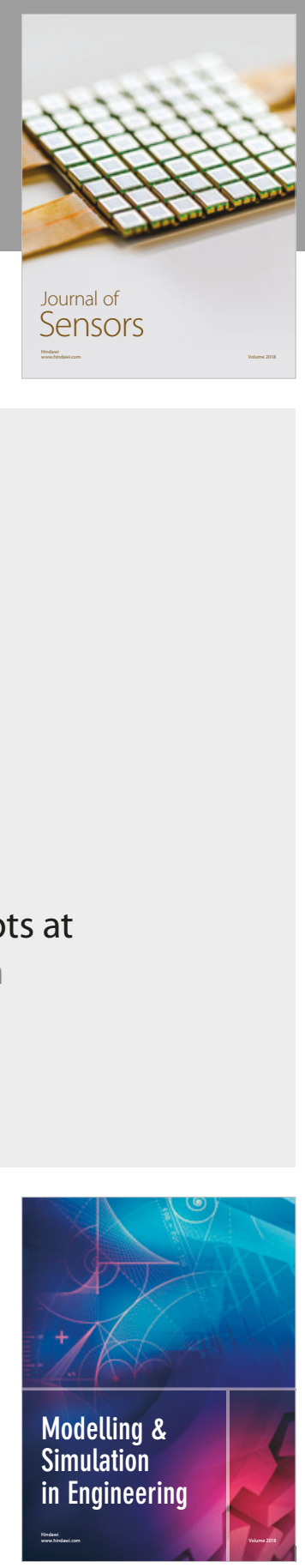

\section{Advances \\ Multimedia}
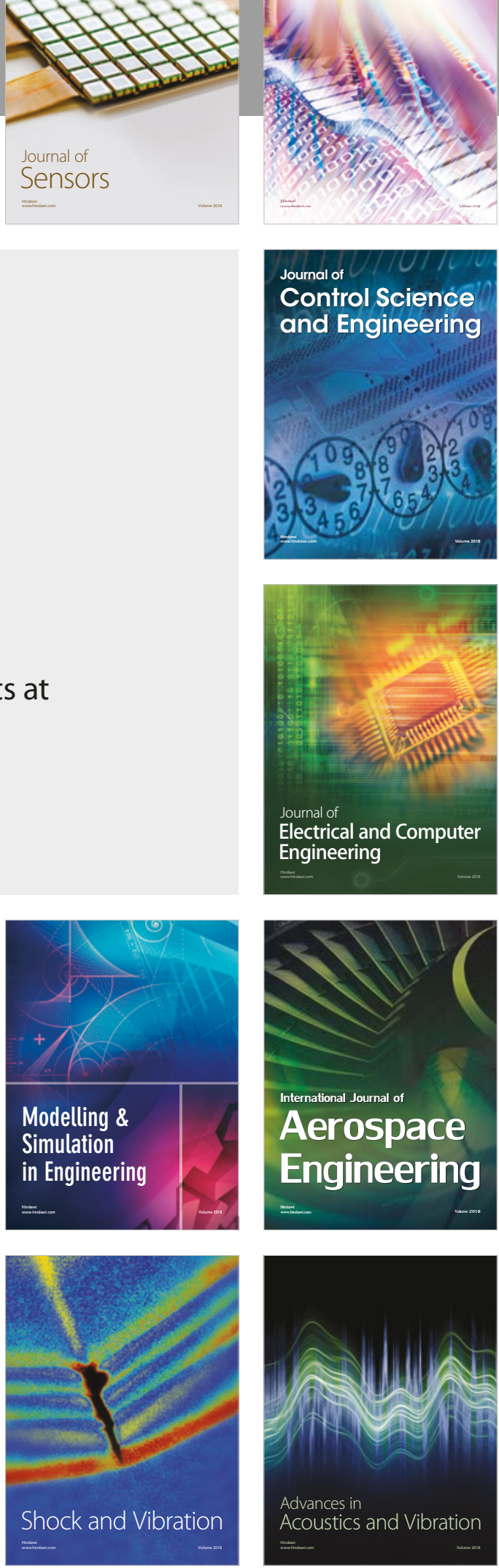